\title{
Aprendizagem significativa como princípio norteador que subsidia a ação docente, sob o enfoque das teorias de Novak e Gowin
}

\author{
Significant learning as a guiding principle that supports teaching action, focusing on \\ the theories of Novak and Gowin
}

\author{
SOUZA, Francicleide Geremias da Costa. Discente do curso de Mestrado em Educação \\ Profissional e Tecnológica \\ Instituto Federal de Educação Ciência e Tecnologia do Sertão Pernambucano- IF Sertão Campus Salgueiro. Salgueiro - PE - \\ Brasil. CEP: 56000-000 /Telefone: (88) 981041277/ francicleidenet@hotmail.com
}

\section{OLIVEIRA, Elineide Pereira. Discente do curso de Mestrado em Educação Profissional e Tecnológica \\ Instituto Federal de Educação Ciência e Tecnologia do Sertão Pernambucano- IF Sertão Campus Salgueiro. Salgueiro - PE - Brasil. CEP: 56000-000 /Telefone: (87) 91038232/ elineide1807@gmail.com}

\section{OLIVEIRA, Cristiane Ayala de. Doutora/Tecnóloga em Agroindústria}

Instituto Federal de Educação Ciência e Tecnologia do Sertão Pernambucano- IF Sertão Campus Salgueiro. Salgueiro - PE Brasil. CEP: 56000-000/ Telefone: (87) 99664-3349 / E-mail: cristiane.ayala@ifsertao-pe.edu.br

\section{ARAÚJO, Ricardo de Andrade. Doutor/Cientista da Computação}

Instituto Federal de Educação Ciência e Tecnologia do Sertão Pernambucano- IF Sertão Campus Salgueiro. Salgueiro - PE Brasil. CEP: 56000-000/ Telefone: (87) 96252209 / E-mail: ricardo.araujo@ifsertao-pe.edu.br

\section{RESUMO}

As teorias educacionais de ensino e aprendizagens têm relevância para prática pedagógica ao proporem novas metodologias que subsidiam a ação docente na perspectiva da aprendizagem significativa. Partindo desse pressuposto, o presente estudo, tem como objetivo relacionar as teorias dos mapas conceituais e do diagrama $\mathrm{V}$ ao conceito de Aprendizagem significativa associando-as à prática docente. Para isso, buscou-se em três bases de dados Scielo, Portal da Capes, Google Acadêmico artigos que abordam as experiências da aplicabilidade e técnica de mapas conceituais como também o "Vê" do Conhecimento na ação do ensino e do aprender. Os descritores: mapas conceituais, aprender, prática docente, Diagrama V, permitiram o estudo de 34 artigos. Percebeu-se que a partir dos anos 70, as novas maneiras de organizar as ideias como propostas para 0 ensino e aprendizagem tornaram-se referência para a efetiva aprendizagem significativa, dando suportes sustentáveis na forma do aprender a aprender. Sendo assim o debate em questão tem motivado a flexibilização da didática e está distante de ser esgotado pelo fato de compreendermos como inovação para melhor desempenho nas salas de aulas.

Palavras-chave: Mapas conceituais, aprender, prática docente, Diagrama V.

\begin{abstract}
Educational theories of teaching and learning have relevance to pedagogical practice by proposing new methodologies that support teaching action from the perspective of meaningful learning. Based on this assumption, the present study aims to relate the theories of concept maps and diagram $V$ to the concept of Meaningful Learning by associating them with teaching practice. For this, we searched in three databases Scielo, Portal da Capes, Google Scholar articles that address the experiences of the applicability and technique of conceptual maps as well as the "See" of Knowledge in the action of teaching and learning. The descriptors: concept maps, learning, teaching practice, Diagram V, allowed the study of 34 articles. From the 1970s onwards, the new ways of organizing ideas as proposals for teaching and learning became a reference for effective meaningful learning, providing sustainable supports in the form of learning to learn. Thus the debate in question has motivated the flexibility of didactics and is far from being exhausted by the fact that we understand as innovation for better performance in classrooms.
\end{abstract}

keywords: Concept Maps, Learning, Teaching Practice, Diagram V. 
SOUZA, F. G. da C.; OLIVEIRA, E. P.; OLIVEIRA, C. A. de; ARAÚJO, R. de A.(2019).

Aprendizagem significativa como princípio norteador que subsidia a ação docente, sob o enfoque das teorias de Novak e Gowin

\section{Introdução}

A aprendizagem significativa está relacionada aos processos de interação entre informações prévias e novas, gerando outras informações que torna o efeito do aprender dinâmico e eficaz quando aplicado às práticas em sala de aula. Segundo Moreira (1995), a aprendizagem cognitiva, afetiva e psicomotora são tipos gerais que se inter-relacionam organizando as informações na mente, cada uma com suas particularidades no processo de aprendizagem. Focando na teoria da aprendizagem significativa, Moreira (1995), destaca que o teórico Ausubel fundamenta-se na aprendizagem cognitiva sem desconsiderar as demais, todavia a sua defesa se faz na "organização do material na estrutura cognitivista". Então,

aprendizagem significativa é um processo por meio do qual uma nova informação relaciona-se com um aspecto especificamente relevante da estrutura de conhecimento do indivíduo, ou seja, este processo envolve a interação da nova informação com uma estrutura de conhecimento específica, a qual Ausubel define como conceito subsunçor, ou simplesmente subsunçor, existente na estrutura cognitiva do indivíduo (Moreira. M. A. (1995 p. 153).

Logo, o entendimento da aprendizagem significativa para a compreensão do desenvolvimento cognitivo dos indivíduos é de grande relevância, pois na relação processual e de ancoragem dos novos saberes aos que já se têm, amplia-se a capacidade de estruturar as habilidades necessárias ao domínio do conhecimento aplicado. "Esta condição implica não só que o material seja suficientemente não-arbitrário em si, de modo que possa ser aprendido, mas também que o aprendiz tenha disponível em sua estrutura cognitiva os subsunçores adequados" (MOREIRA, p. 156, 1995). Portanto, a ação docente em sala de aula, nos contextos atuais, apresenta-se desafiante, visto que sob a ótica da aprendizagem significativa exigirá dos professores o reconhecimento acerca dos conhecimentos prévios dos educandos. Sendo assim, a busca por técnicas, recursos, métodos e estratégias tem assumido um lugar destaque na prática pedagógica, pois no universo dinâmico da escola exige outros perfis das aulas (DA SILVA, 2015).

Apresenta-se neste artigo a importância da teoria dos mapas conceituais, elaborada nos anos 70 pelo professor Joseph D. Novak que direcionou a uma "aprendizagem específica" denominada Aprendizagem significativa, pois "um mapa conceptual é um recurso esquemático para representar um conjunto de significados conceptuais incluídos numa estrutura de proposições" (NOVAK, p. 31, 1984). Ainda, na linha da defesa das metodologias para a prática docente, destacamos o diagrama "V", do professor D. Bob Gowin, atestando a teoria do David Ausubel, ratifica que "para aprender significativamente, o indivíduo deve optar por relacionar os novos conhecimentos com as proposições e conceitos relevantes que já conhece" (NOVAK, p. 31, 1984 ). Gowin foi autor da invenção do instrumento heurístico que objetiva as pessoas a compreender a estrutura do conhecimento como o processo de construção, conforme o descreveu no livro Aprender a aprender (1984). Então, na pretensão da utilidade, algumas questões devem ser consideradas:

Quando os estudantes estão confusos a respeito dos novos conceitos que tentam aprender, o problema está normalmente aqui, no vértice do " $\mathrm{V}$ ". 
SOUZA, F. G. da C.; OLIVEIRA, E. P.; OLIVEIRA, C. A. de; ARAÚJO, R. de A.(2019).

Aprendizagem significativa como princípio norteador que subsidia a ação docente, sob o enfoque das teorias de Novak e Gowin

Os estudantes têm de ser ajudados a reconhecer (1) quais os acontecimentos ou objectos que eles estão a observar, (2) quais os conceitos que eles já conhecem que se relacionam com estes acontecimentos ou objectos, e (3) quais os registos que vale a pena fazer, (NOVAK e GOWIN,1984, p. 22)

Partindo desse contexto, consideramos que a ferramenta "V" do conhecimento contribui significativamente para a agregação firme do conhecimento, promovendo uma significativa aprendizagem. Assim, os conceitos e registros de acontecimentos (a que chamamos fatos), aparecem unidos e estão intimamente interligados quando tentamos produzir conhecimentos novos (ALVES, 2017). Considerando que o mapa conceitual e o Diagrama em "V" são estratégias facilitadoras da aprendizagem significativa, se constituindo como técnicas adaptáveis às diversas situações, sendo ferramentas para recurso de aprendizagem, avaliação e método didático. 0 estudo propõe relacionar as teorias dos mapas conceituais e do diagrama "V" ao conceito de Aprendizagem significativa associando-as à prática docente.

\section{Mapas conceituais}

As teorias da aprendizagem, "resultam das tentativas feitas pela psicologia de organizar observações, hipóteses, palpites, leis, princípios e conjecturas feitos acerca do comportamento humano", e têm se tornado cada vez mais complexas ao longo do tempo.

O behaviorismo, que está associado a diversos teóricos, dentre os quais, B. F. Skinner, Edward Thorndike, John B. Watson, Edwin Guthrie, apresenta diversas vertentes. Os behavioristas buscam esquadrinhar o comportamento dos animais e humano, focando nos fatos e objetivos (reações e estímulos), sem observar conteúdos vinculados aos estados mentais. Em um caminho divergente em relação ao Behaviorismo, o cognitivismo se envolve essencialmente "com os eventos intelectuais como solução de problemas, processamento de informação, pensamento e imaginação" (SKINNER; 1972).

A Teoria de Piaget enfatiza a gênese - desenvolvimento - do conhecimento e pode ser simplificada conforme as afirmações:

- A aquisição do conhecimento é um processo desenvolvimentista gradual que se torna possível pela interação da criança com o ambiente.

- A sofisticação da representação do mundo pelas crianças é uma função do seu estágio de desenvolvimento. Esse estágio é definido e pelas estruturas de pensamento que elas possuem na ocasião.

- Maturação, experiência ativa, equilibração e interação social são as forças que moldam a aprendizagem (Piaget, 1961).

A Teoria de Piaget teve um impacto profundo nas práticas pedagógicas e deu origem à Abordagem Construtivista, o qual o aluno deixa de ser visto como receptor passivo de conhecimento e passa a ser encarado como agente da construção da sua própria estrutura cognitiva (Piaget, 1976). David Ausubel desenvolveu estudos visando aplicações diretas para o processo ensino-aprendizagem em sala de aula, pode ser enquadrado como um cognitivista/construtivista onde a aprendizagem se 
SOUZA, F. G. da C.; OLIVEIRA, E. P.; OLIVEIRA, C. A. de; ARAÚJO, R. de A.(2019).

Aprendizagem significativa como princípio norteador que subsidia a ação docente, sob o enfoque das teorias de Novak e Gowin

dá na organização e integração das novas informações à estrutura cognitiva do indivíduo (Moreira, 1999). Para Ausubel no processo ensino- aprendizagem as novas informações poderão ser mais facilmente aprendidas e retidas, quando já existirem conceitos prévios na estrutura cognitiva do aluno e que sirvam de ancoradouro para os novos conceitos. A definição mais importante da obra de Ausubel é a de aprendizagem significativa (MOREIRA, 2006).

Os mapas conceituais desenvolvidos por Joseph Novak na década de 1970 apresentam-se como ferramentas alternativas para mudança na prática docente no sentido de organizar e comunicar conhecimentos, onde o professor pode utilizá-lo para introduzir conceitos, realizar novas sínteses e processos avaliativos. Os mapas podem ser construídos e apresentados pelos próprios alunos sem a dispensa da explicação do professor ( RUIZ-MORENO, et al, 2007).

A utilização dos mapas conceituais nos processos avaliativos decorre de percepções sobre como o aluno estar organizando os conhecimentos em sua estrutura cognitiva. Durante esse processo o professor poderá intervir auxiliando-o na superação de dificuldades, por sua vez o aluno poderá desenvolver aspectos positivos, habilidades e competências (PACHECO; DAMASIO, 2009). Segundo Ruiz-Moreno, et al (2007), no processo de avaliação a construção de mapas conceituais envolve critérios quantitativos e pontos que devem ser levados em consideração: conceitos: quantidade e qualidade e seu nível de hierarquização; inter-relações entre conceitos: número de linha de ligação e proposições entre eles; Estrutura do mapa: presença ou não de relações cruzadas que mostra se mapa é sequencial ou em rede.

O diagrama em $\mathrm{V}$, proposto por Gowin é uma metodologia que relaciona elementos entre as questões básicas relativas ao conteúdo que está sendo estudado e o domínio conceitual e metodológico. Pode ser utilizado em aulas expositivas, experimentos em sala de aula, análise de currículos e processos avaliativos. Na avaliação não será para diagnósticos, mas para conhecer as condições atuais e reais do estudante, de forma a favorecer-lhe avanços e superações (ROSA, 2009).

Segundo Barbosa e Moura (2013), a inserção de metodologias inovadoras na Educação Profissional e Tecnológica-EPT são mudanças necessárias para a formação de indivíduos tecnicamente preparados para o mundo do trabalho para que eles sejam capazes de exercer valores e condições de formação humana considerados essenciais no mundo contemporâneo. É necessário que as mudanças aconteçam, embora um decreto não resolva o problema das metodologias obsoletas, ou inadequadas para novos conteúdos no cenário da EPT, são nos espaços de discussão e na criação de ambientes de aprendizagem contextualizada que a aprendizagem significativa tem relevância, e se apresenta como contribuição na criação de ambientes de aprendizagem contextualizada, com impactos de grande interesse para a formação na EPT ( MACHADO, 2008).

O espaço onde as relações entre professor e aluno acontecem, ou seja, o ambiente da sala de aula revelam as limitações que mais afetam a eficiência do sistema educacional em todos os níveis e tipos de ensino. 0 aperfeiçoamento e as inovações é um complemento necessário para a construção do conhecimento ( AGUIAR, 1995).

A discussão sobre as metodologias de aprendizagem ditas ativas nos espaços da EPT, ainda em patamares discretos apresentam-se como oportunidades de se construir o conhecimento de forma efetiva e dinâmica. Segundo Araújo (2009), aprendizagem ativa, conceituada também de apren- 
SOUZA, F. G. da C.; OLIVEIRA, E. P.; OLIVEIRA, C. A. de; ARAÚJO, R. de A.(2019).

Aprendizagem significativa como princípio norteador que subsidia a ação docente, sob o enfoque das teorias de Novak e Gowin

dizagem significativa, ocorre quando o aluno interage com o assunto em estudo - ouvindo, falando, perguntando, discutindo, fazendo e ensinando - sendo estimulado a construir o conhecimento ao invés de recebê-lo de forma passiva do professor.

A atitude do aluno de pensar, fazer e sentir aquilo que se está fazendo é o grande diferencial que caracteriza um ambiente de aprendizagem ativa. A participação dos sentimentos deve ser vista como um fator relevante na fixação do conhecimento (SHAH; NIHALANI, 2012).

Ribeiro (2005), afirma que a aprendizagem se torna mais significativa com uso das metodologias ativas de aprendizagem. A tomada de decisão, aquisição de confiança e aplicação do conhecimento em situações práticas é percebido em alunos que vivenciaram esses métodos. Há assim melhora no relacionamento com os colegas, aprendem a se expressar oralmente e por escrito, adquirem gosto para resolver problemas e vivenciam situações que requerem tomar decisões por conta própria.

A adequabilidade dos métodos ativos para EPT oferece oportunidades nas diferentes áreas de formação profissional. Podem ser trabalhadas nas oficinas, aulas de laboratório, tarefas em grupo, trabalhos em equipe dentro e fora do ambiente escolar, visitas técnicas e desenvolvimento de projetos. 0 envolvimento do aluno no processo de aprendizagem se torna natural, dinâmico e produtivo (UVINHA, 2010). No entanto enfrenta-se muitos desafios pedagógicos nos tempos modernos, ou seja, incorporar aprendizagem ativa nos espaços e tempos atualmente ocupados pelas tradicionais aulas expositivas encontra-se em construção, devendo ser colocado a discussão e provocações, no cotidiano da formação dos educadores ( GODOY, 2009).

\section{Material e métodos}

Trata-se de uma revisão integrativa da literatura, metodologia que proporciona a síntese do conhecimento e incorporação da aplicabilidade de resultados de estudos significativos na prática (CARVALHO; SILVA; SOUSA; 2010).

A busca na literatura se deu por meio de uma sequência de passos: (1) identificação do tema para a elaboração da revisão integrativa;(2) estabelecimento dos critérios de inclusão e exclusão; (3) definição das informações dos estudos selecionados;(4) avaliação dos estudos (5) interpretação dos resultados e apresentação da revisão (FERENHOF et al, 2016).

Foram estabelecidos os seguintes critérios de inclusão: artigos científicos publicados nos últimos cinco anos (2015 a 2019) com enfoque nas teorias educacionais dos autores Novak e Gowin, destacando o uso dos mapas conceituais e Diagrama em "V", na prática do professor nas disciplinas em sala de aula. Como critério de exclusão estudos que abordam outras teorias educacionais, relatórios de estágio, teses, artigos que abordam outras linhas do conhecimento que não vivenciados no contexto da sala de aula. A pesquisa foi realizada em três bases de dados: Scielo, Portal da CAPES, Google Acadêmico, utilizando como descritores: Mapas conceituais, aprender, prática docente, Diagrama "V".

Foram identificados quarenta e quatro artigos no portal da CAPES e selecionados apenas nove deles, na Scielo encontramos vinte e um e elegeram-se quatro, na base de dados Google 
SOUZA, F. G. da C.; OLIVEIRA, E. P.; OLIVEIRA, C. A. de; ARAÚJO, R. de A.(2019).

Aprendizagem significativa como princípio norteador que subsidia a ação docente, sob o enfoque das teorias de Novak e Gowin

Acadêmico 447 identificou-se 140 dentro da temática e selecionamos 21 que se enquadravam no contexto desse artigo. Em um total de 34 artigos que abordam experiências no ensino médio, ensino fundamental e vivências em formação inicial de professores.

\section{Resultados e discussão}

Os fundamentos que justificam a criação do livro aprender a aprender segundo Novak e Gowin alicerçam-se no conhecimento que pode ser construído a partir de conceitos já existentes, e existe uma simbiose entre o desenvolvimento teórico e as estratégias educacionais onde uma das melhores opções para os educadores é a mudança nos métodos de se conceber a aprendizagem. Enfoca também que a aprendizagem é algo próprio e único de cada pessoa, o conhecimento é coletivo e compartilhado (NOVAK e GOWIN, 1996). Para esses autores,

Embora a mesma experiência possa ser partilhada pelas crianças mais novas e pelas mais velhas, pelos peritos e pelos novatos, pelos aprendizes e pelos mestres, o significado dessa experiência pode ser radicalmente diferente para cada um deles. A educação é o processo através do qual procuramos activamente mudar o significado da experiência. A educação pode ser libertadora ou opressiva; este livro pretende tornar a educação mais libertadora. (NOVAK e GOWIN, 1996, p.21)

Os mapas conceituais compreendidos como diagramas hierárquicos que indicam relações entre conceitos. Representam uma fotografia instantânea da estrutura cognitiva do aprendiz, não deve ser julgado como um mapa certo ou errado, mas a forma como está representado no seu raciocínio pessoal naquele determinado instante (JUNIOR, SHIRLEY, 2017). Os mapas conceituais devem seguir uma hierarquia; isto é, os conceitos mais gerais devem situar-se no topo do mapa, seguidos dos conceitos cada vez mais específicos, colocados sucessivamente debaixo deles (NOVAK e GOWIN, 1996).

Figura 1- Mapa de conceitos mostrando as ideais e características que envolve a construção de mapas de conceitos.

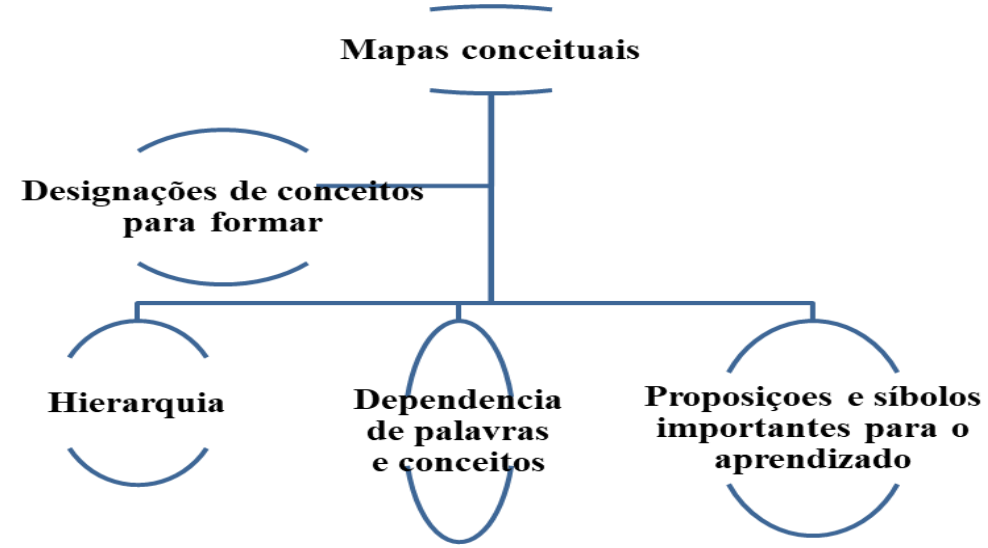

Fonte: livro Aprender a Aprender (NOVAK e GOWIN, 1996). 
SOUZA, F. G. da C.; OLIVEIRA, E. P.; OLIVEIRA, C. A. de; ARAÚJO, R. de A.(2019).

Aprendizagem significativa como princípio norteador que subsidia a ação docente, sob o enfoque das teorias de Novak e Gowin

O “V” Heurístico, também conhecido como Vê de Gowin, foi proposto por D. B. Gowin, em 1981, com o objetivo de ilustrar os elementos conceptuais e metodológicos que interagem no processo de construção do conhecimento (LUCAS et al, 2017). O formato de V do diagrama (Quadro 02) permite evidenciar a produção do conhecimento a partir do resultado da interação de dois domínios: o teórico conceitual, no qual estão localizados os conceitos e princípios que poderão ser transformados em teorias (lado esquerdo do V, lado do 'pensar'), e o domínio metodológico, que corresponde ao lado direito do V, lado do 'fazer', no qual a partir de registros obtidos durante uma atividade ou experimentação chega-se aos dados que podem respondem uma questão foco ( Moreira , 2007).

Figura 02- Vê epistemológico de Gowin e seus componentes.

\section{O DIAGRAMA V}

\section{Fenômeno de} interesse

DOMÍNIO TEÓRICO CONCEITUAL (Pensar)

FIL OSOFIA(S): visões de mundo, crenças gerais, abrangentes, profundas, sobre a natureza do conhecimento que subjazem sua produção

TEORIA(S): conjunto(s) organizado(s) de princípios e conceitos que guiam a produção de conhecimentos, explicando porque eventos ou objetos exibem o que é observado

PRINCÍPIO(S): enunciados de relações entre conceitos que guiam a ação explicando como se pode esperar que eventos ou objetos se apresentem ou comportem

CONCEITO(S): regularidades percebidas em eventos ou objetos indicados por um rótulo (a palavra conceito

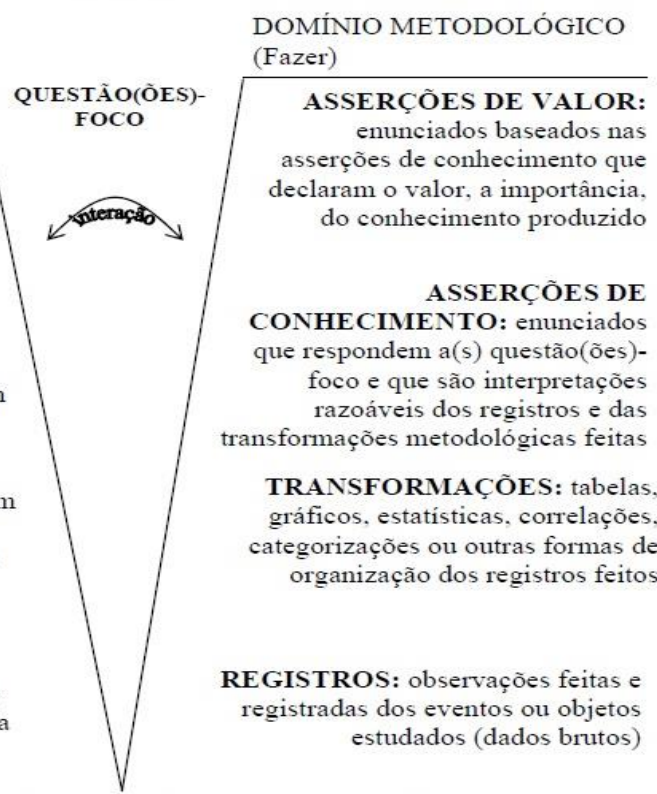

EVENTOS/OBJETOS: descrição do(s) evento(s) e/ou objeto(s) a $\operatorname{ser}(\mathrm{em})$ estudado(s) a fim de responder a(s) questão(ões)-foco

Fonte: Moreira (2007, p. 3)

Na base do vê são localizados os objetos ou eventos a serem estudados, a fim de fazer o registro dos mesmos para que possam ser estudados. A questão foco está localizada ao centro do "V" (questão chave), região que pertence tanto ao lado metodológico quanto ao teórico conceitual. As questões centrais focam a atenção sobre certos acontecimentos e objetos que devem ser respondidas de acordo com a interação dos dois lados. Os elementos conceptuais da parte esquerda do "Vê" são possíveis respostas as indagações, eles são construções (concepções) que se têm desenvolvido ao longo do tempo, enquanto os elementos da parte direita se constroem em função 
SOUZA, F. G. da C.; OLIVEIRA, E. P.; OLIVEIRA, C. A. de; ARAÚJO, R. de A.(2019).

Aprendizagem significativa como princípio norteador que subsidia a ação docente, sob o enfoque das teorias de Novak e Gowin

da investigação que se esta fazendo no momento (NOVAK e GOWIN, 1996).

A pesquisa de Dantas, Silva \& Borges (2018), que busca afirmar "uso dos mapas conceituais como ferramenta de avaliação qualitativa, com ênfase no ensino de física", após realizarem a pesquisa bibliográfica concluíram que os "mapas conceituais são ótimas ferramentas para a avaliação qualitativa". Em outra discussão, Vinholi Junior \& Princival (2014), no texto "modelos didáticos e mapas conceituais: biologia celular e as interfaces com a informática em cursos técnicos do IFMS" buscaram elaborar uma sequência didática, utilizando os mapas conceituais como ferramentas pedagógicas para inferência da aprendizagem significativa, o que segundo eles, após trabalharem com os estudantes, verificaram dificuldades de apropriação na estrutura gráfica, principalmente na formulação de conceitos e proposições. Porém, concluem que "viabilidade do uso de Mapas Conceituais em um tipo de atividade que envolve novidades e descobertas, depende da forma como a prática foi adotada e utilizada pelo docente". Podemos acrescentar as discussões dos dois referenciais supracitados que a técnica dos mapas de conceitos pode ser um material de uso pedagógico preciso na aplicação da teoria cognitivista do Ausubel. Todavia, compreendemos que o recurso foi utilizado como experimento estático o que se faz necessário uma exploração mais intensa do uso do recurso. Resultados similares com trabalho realizado na turma $3^{\circ}$ ano de uma escola da rede privada de Joinville, nos conteúdos das disciplinas de Ciências e História com a confecção de mapas conceituais feitos pelos alunos destacou relatos dos alunos onde as informações colocadas nos mapas ficaram mais claras e objetivas com fácil compreensão, sem a necessidade de memorizar termos, desenvolvendo a habilidade de estruturarem as informações ( GODOY, 2017).

Soares e Pinto (2016), no desenvolvimento da atividade com "190 alunos (95 duplas) do $2^{\circ}$ ano do Ensino Médio do Colégio Estadual Imigrante, localizado no município de Caxias do Sul”, buscaram aplicar conhecimentos prévios para relacionar os conceitos sobre o Reino Protista ao planejamento, a coerência e autonomia. Para isso, distribuíram 43 palavras-chaves conceituais para que os estudantes elaborassem o trabalho. Então, chegaram à conclusão que "pode evidenciar a importância da utilização de mapas conceituais como ferramenta no processo de ensinoaprendizagem e aprendizagem significativa". Mais uma vez, evidencia-se que as práticas docentes que utilizam da teoria do Novak, tem maior probabilidade da aprendizagem significativa ser apropriada pelos estudantes.

Para Gowin (1981), os espaços de sala de aula são ambientes propícios para experimentação de novas metodologias, é nesse espaço que a construção do conhecimento se dar por varáveis que muitas vezes fogem ao controle do professor se revelando como algo que deve ser positivo ou negativo para a construção do conhecimento. No âmbito do ensino de ciências o Diagrama $V$ tem sido utilizado como instrumento facilitador da aprendizagem e avaliação. Segundo Lucken et al (2017), experimento realizado no acompanhamento da aprendizagem de conteúdos de ciências em um $5^{\circ}$ ano do Ensino Fundamental de uma escola pública, da região norte do Paraná - Brasil, houve uma boa aceitação dos alunos a esse recurso.A utilização do referido diagrama mostrou-se viável e muito interessante, oferecendo encaminhamentos desafiadores aos alunos e professores que puderam observar, ao final das atividades os novos conceitos adquiridos frente aos conhecimentos prévios elencados no início de todo o processo interventivo. 0 diagrama em $\mathrm{V}$ nesse experimento se 
SOUZA, F. G. da C.; OLIVEIRA, E. P.; OLIVEIRA, C. A. de; ARAÚJO, R. de A.(2019).

Aprendizagem significativa como princípio norteador que subsidia a ação docente, sob o enfoque das teorias de Novak e Gowin

mostrou efetivo no processo de avaliação da aprendizagem, pois há uma interação entre os conceitos já existentes trazidos pelos estudantes e a construção de novos, mediante o conteúdo que é apresentado ao aluno naquele momento.

Experiência positiva vivenciada no município de Serra, Estado do Espírito Santo utilização do Diagrama Vem atividades na disciplina de física experimento com Magnetismo em sala de aula de ensino médio, turma da $3^{\text {a }}$ série de uma escola estadual pública. Os próprios alunos foram responsáveis pela elaboração das questões focos no diagrama permitido assim a visualização do objetivo da atividade a ser executada. Foi possível mapear erros conceituais cometidos pelos estudantes que muitas vezes não são identificados em relatórios tradicionais, assim como a construção do passo a passo de diagrama orientou a atividade construindo o conhecimento e dando significado a aprendizagem para os estudantes (PRADO; FERRACIOLI, 2017).

Segundo Rosa et. al, (2018), o trabalho realizado com a formação inicial de professores de Química,desenvolvido por bolsistas do PIBID licenciados em Química pela Universidade Federal do Espírito Santo a confecção de materiais educativos segundo as necessidades de aprendizagem dos alunos e análise através do instrumento heurístico V de Gowin, desenvolvido por bolsistas do PIBID licenciados em Química pela Universidade Federal do Espírito Santo, permitiu atribuírem novos significados as metodologias de ensino utilizadas superando os métodos de ensino estáticos pela construção dos saberes com dinamicidade vislumbrando ações significativas na ação docente.

\section{Conclusões}

Constatou-se que as estratégias metodológicas gráficas têm importante função na representação, organização e criação dos saberes através de relações de conceitos, formulando proposições que sustentam a aprendizagem significativa. São metodologias que devem ser incorporadas a didática do professor embora consideradas não habituais nos espaços educacionais. 0 ambiente escolar especificamente a sala de aula é o espaço de grandes descobertas, aliado aos conhecimentos já trazidos pelos estudantes, o professor pode superar limites concebendo um potencial significativo na construção de saberes.

O docente é o mediador, orienta e ao mesmo tempo aprende, superando os limites de aprendizagens advindos apenas da teoria, nessa perspectiva as ações pedagógicas com métodos inovadores tornam-se eixos estruturantes dos saberes práticos necessários à profissão. É necessário enfatizar que na formação inicial dos professores sejam incorporados essas fazeres inovadores como algo prazeroso nas atividades escolares e edificantes para a construção do conhecimento.

No referido estudo, verificamos um número acentuado de teses sobre o "V" de Gowin em detrimento ao número pequeno de artigos publicados, há um maior número de artigos direcionados as experiências vivenciadas no ensino médio destacando lacunas de publicações nos anos escolares iniciais, nessa perspectiva ficam as contribuições da pesquisa para novos estudos nessa linha.

Constatou que o diagrama $\mathrm{V}$ e mapas conceituais já foram esperiênciados em salas de aulas dos cursos técnicos e em instituições de Educação Profissional e Tecnológica, com resultados positivos, 
SOUZA, F. G. da C.; OLIVEIRA, E. P.; OLIVEIRA, C. A. de; ARAÚJO, R. de A.(2019).

Aprendizagem significativa como princípio norteador que subsidia a ação docente, sob o enfoque das teorias de Novak e Gowin

trazendo ao aluno a reflexão sobre a importância da aquisição do conhecimento de forma eficiente e participativa, adquirido no sentido de desenvolvimento de habilidades e competências necessárias a sua formação para atividades laborais e no exercício da cidadania.

\section{Referências}

AGUIAR, J. O. G. Mudança conceitual em sala de aula: o ensino de ciências numa perspectiva construtivista. 1995. Dissertação (Mestrado em Educação Tecnológica) - Cefet-MG, Belo Horizonte, 1995.

ARAÚJO, Ulisses F. Aprendizagem baseada em problemas no ensino superior. São Paulo: Summus, 2009.

A. J. VINHOLI JÚNIOR1 e G. C. PRINCIVAL. Modelos Didáticos E Mapas Conceituais: Biologia Celular E As Interfaces Com A Informática Em Cursos Técnicos Do IFMS. HOLOS, Ano 30. Vol. 2

ALVES, Vitória Jamille Lira. O fazer não pressupõe o aprender: o uso do V de Gowin no Laboratório de Química Fundamental. 2017.

BUENO LUCAS, Lucken et al. A utilização do vê epistemológico de gowin no ensino de ciências como um instrumento não tradicional de avaliação da aprendizagem. Enseñanza de las ciencias, n. Extra, p. 5267-5274, 2017

BARBOSA, Eduardo Fernandes; DE MOURA, Dácio Guimarães. Metodologias ativas de aprendizagem na educação profissional e tecnológica. Boletim Técnico do Senac, v. 39, n. 2, p. 48-67, 2013.

CARVALHO.R; SILVA.D.M; SOUZA.T.M. Revisão integrativa: o que é e como fazer. Rev. Einstein; n.1; V.8; 2010.

DO PRADO, Ramon Teodoro; FERRACIOLI, Laercio. Utilização do Diagrama $V$ em atividades experimentais de magnetismo em sala de aula de ensino médio. Revista do Professor de Física, v. $1, \mathrm{n}$. 1 , p. $1-14,2017$

DA SILVA, Edson Coutinho. Mapas Conceituais: propostas de aprendizagem e avaliação. Administração: Ensino e Pesquisa, v. 16, n. 4, p. 785-815, 2015.

FERENHOF, Helio Aisenberg; FERNANDES, Roberto Fabiano. Desmistificando a revisão de literatura como base para redação científica: método SSF. Revista ACB, v. 21, n. 3, p. 550-563, 2016.

GUIMARÃES, Maria Inês Sabino. O uso de tecnologias de informação para a construção de conhecimentos nos sistemas de aprendizagem no ensino médio integrado do IFMG (Dissertação de mestrado). Projetos, Dissertações e Teses em Sistemas de Informação e Gestão do Conhecimento, v. 5, n. 2, jul-dez, 2016. Disponível em < http://www.fumec.br/revistas/sigc/issue/view/264> Acesso em 10 Abr 2019.

GOMES, I. S.; CAMINHA, I. D. O. Guia para estudos de revisão sistemática: Uma opção metodológica para as ciências do movimento humano. Movimento, v. 20, n. 1, p. 395-411, 2014.

GODOY, E. G. U. Contribuições da metodologia de projetos na implantação das tecnologias de informação e comunicação - TIC nos processos educativos da educação básica. Dissertação (Mestrado em Educação Tecnológica) - Cefet-MG, Belo Horizonte, 2009.

GODOY, Lilian Miranda et al. O uso dos mapas conceituais no $3^{\circ}$ ano do ensino fundamental I. 2017.

JUNIOR, Airton José Vinholi; GOBARA, Shirley Takeco. A Construção de Conceitos sobre a Estrutura e a Fisiologia Celular por meio de Mapeamento Conceitual. Acta Scientiae, v. 19, n. 6, 2017. 
SOUZA, F. G. da C.; OLIVEIRA, E. P.; OLIVEIRA, C. A. de; ARAÚJO, R. de A.(2019).

Aprendizagem significativa como princípio norteador que subsidia a ação docente, sob o enfoque das teorias de Novak e Gowin

SKINNER, B. F. HUMANISMO E BEHAVIORISMO. Humanist, 1972.

MACHADO, L. R. de S. Diferenciais inovadores na formação de professores para a educação profissional. Revista Brasileira de Educação Profissional e Tecnológica, Brasília, DF, v. 1, n. 1, jun. 2008.

Moreira, M.A. (1999). Teorias de aprendizagem. São Paulo: EPU.

Moreira, M.A. (2006). A teoria da aprendizagem significativa e suas implementações em sala de aula. Brasília: Editora Universidade de Brasília.

Moreira, M.A. (1995). Monografia n" 10 da 5th-ie Enfoques Teóricos. Porto Alegre. Instituto de Física da UFRGS. Originalmente divulgada, em 1980, na série "Melhoria do Ensino", do Programa de Apoio ao Desenvolvimento do Ensino Superior (PADES)/ UFRGS, N" 15. Publicada, em 1985, no livro "Ensino e aprendizagem: enfoques teóricos", São Paulo, Editora Moraes, p. 61-73_Revisada em 1995.

Moreira, M. A. (2007). Diagramas V e Aprendizagem Significativa. Disponível em <http://www.if.ufrgs.br/ moreira/DIAGRAMASpor.pdf

M. P. DANTAS, F. U. SILVA, J. C. S. BORGES. Uso Dos Mapas Conceituais Como Ferramenta De Avaliação Qualitativa, Com Ênfase No Ensino De Física. Holos, Ano 34, Vol.03, 2018.

NOVAK, Joseph Donald; GOWIN, D. Bob; VALADARES, Carla. Aprender a aprender. 1996.

NOVAK, Joseph D; GOWIN, D. Bob. Aprender a Aprender. Paralelo Editora, LDA. Lisboa, 1984.

SHAH, S.; NIHALANI, M. Stress free environment in classroom: impact of humor in student satisfaction. Munich: GRIN Publishing, 2012. Disponível em: <http://www.grin.com/en/ebook/192216/stress-freeenvironment-in-classroom-impact-of-humor-in-student-satisfaction\#inside>. Acesso em: 17 Abr. 2019.

RIBEIRO, R. de C. A aprendizagem baseada em problemas (PBL): uma implementação na educação em engenharia. Tese (Doutorado) - UFSC, Florianópolis, 2005.

RUTZ DA SILVA, S.; BRINATTI, A.; CHAVES DE ANDRADE, A. A experiência das disciplinas de formação docente em ensino de Física no MNPEF-UEPG: proposta pedagógica, reflexões e ações. Revista Espaço Pedagógico, v. 25, n. 2, p. 339-363, mai/ago 2018. DOI: https://doi.org/10.5335/rep.v25i2.8168 Acesso em 02 Abr. 2019.

Ruiz-Moreno, L.; Sonzogno, M.C.; Batista, S.H.S. e Batista, N.A. (2007). Mapa conceitual: ensaiando critérios de análise. Ciência Educação, 13, 453-463.

Rosa, P. R. (2009). O "V" epistemológico de Gowin. Universidade Estadual de Mato Grosso do Sul. Retirado em 15/04/2019, no World Wide Web: http: / fisica.uems.br/arquivos/ instrumentacao

ROSA, Débora Lázara; MENDES, Ana Néry Furlan; LOCATELLI, Andrea Brandao. A formação da identidade docente na licenciatura em química e suas relações com a aprendizagem significativa a partir da análise do modelo de ensino de Gowin. Revista Práxis, v. 10, n. 20, p. 147-160, 2018.

SOARES, Luana Gonçalves; Pinto, Jocelei Maria de Oliveira. Aprendizagem Significativa na Construção de Mapas Conceituais. SCIENTIA CUM INDUSTRIA, V.4, N.4, 241-243, 2016.

SANTOS, Roberto Vatan dos. Abordagens do processo de ensino e aprendizagem. Integração, São Paulo, ano XI, n.40, p.19-31, jan/fev/mar, 2005. Disponível em <https://social.stoa.usp.br/articles/0034/1812/abordagens_de_processo_de_ensino_e_aprendizage m.pdf> Acesso em 14 Abr. 2019.

PACHECO, Sabrina Moro Villela; DAMASIO, Felipe. Mapas conceituais e diagramas V: ferramentas para o ensino, a aprendizagem e a avaliação no ensino técnico. Ciências \& Cognição, v. 14, n. 2, p. 166-193, 2009. 
SOUZA, F. G. da C.; OLIVEIRA, E. P.; OLIVEIRA, C. A. de; ARAÚJO, R. de A.(2019).

Aprendizagem significativa como princípio norteador que subsidia a ação docente, sob o enfoque das teorias de Novak e Gowin

PIAGET, J. (1976). A equilibração das estruturas cognitivas (Penna, M.M.S., Trad.). Rio de Janeiro: Jorge Zahar.

PIAGET, J. Les Mécanismes Perceptifs. Paris: PUF, 1961

UVINHA, R. R.; PEREIRA, D. Metodologias ativas de aprendizagem no ensino de ciências humanas e sociais. Comciência: revista eletrônica de jornalismo científico, 10 fev. 2010. Disponível em: http: / / www.comciencia. br/comciencia/?section=8\&edicao=53\&id $=673$ 